\title{
O CIRURGIÃO E A ATUAL CONJUNTURA
}

\section{THE SURGEON AND THE CURRENT CONJUNCTURE}

\author{
Alberto Schanaider-TCBC-RJ
}

\begin{abstract}
RESUMO: A formação profissional do cirurgião demanda longos anos e se estende muito além do Curso de Graduação. A aquisição de destrezas para o exercício da prática profissional será aperfeiçoada na Residência Médica, mas tão somente a atuação nos diversos cenários que se apresentam no campo cirúrgico irá prepará-lo para as intempéries do campo operatório. A realização de uma pósgraduação stricto sensu não lhe trará bagagem para a atividade assistencial, mas desenvolverá o gosto pelo ensino, pesquisa e quiçá servirá de estímulo para uma opção a carreira docente (Rev. Col. Bras. Cir. 2008; 35(3): 207-209).
\end{abstract}

Descritores: Educação Médica; Cirurgião; Ensino.

\section{A FORMAC̄̃O PROFISSIONAL E SEUS CONFLITOS}

Para galgar a alcunha de cirurgião experiente, o novato terá de passar por algumas etapas inevitáveis. Deverá superar a insegurança inicial e libertar-se do cordão umbilical de seus professores-tutores. Já na sua adolescência cirúrgica, buscará a auto-suficiência e enquanto aperfeiçoa a técnica, seu eventual desprendimento, por vezes, se transmutará em arrogância, pois adquirirá o hábito de contestar os ensinamentos de seus mestres, encorajado pelo suposto domínio do seu mister. Ao amadurecer seu exercício profissional, buscará consolidar seu conhecimento, desta feita, mais cauteloso e cônscio de suas limitações, e ciente de que as demandas jurídicas estarão sempre a espreita dos açodados, imprevidentes e despreparados. Procurará manter-se em atividade até onde o livre arbítrio e a saúde lhe permitirem, ou valer-se-á do bom senso da família ou dos amigos mais íntimos que, reservadamente, o farão entender sobre o oportuno momento de encerrar esta missão tão nobre. Adoecer ao longo desta jornada pode ser catastrófico ao profissional liberal, se não houver uma alternativa para o suporte financeiro. Mas caso isto ocorra, mesmo que se trate de uma limitação temporária, é estratégico evitar que seus pares e ou pacientes saibam que você é o enfermo, porquanto, ao primeiro sinal de fragilidade se lhe dirão que lá se foi a firmeza das mãos.

Discípulos não mais existem. Há assistentes e que ser forem confiáveis poderão, com competência e sorte, nem sempre nesta ordem, herdar a clínica e quiçá, farão jus ao nome de seu predecessor. Nas escolas não há mais os grandes cirurgiões, referências regionais e nacionais na especialidade, pois estes se esvaíram na massificação do ensino e na expansão desenfreada do quantitativo dos profissionais médicos. Diga-se de passagem, este é um capítulo a parte, no cenário formativo, cujas previsões mais otimistas limitam a cerca de duas centenas as Faculdades de Medicina, antes do final desta década ${ }^{1,2}$.

Todavia um dos grandes geradores de conflitos na carreira é a relação médico-paciente. Será que nós, cirurgiões, já nos apercebemos, que nos tempos atuais o paciente deixou de ser considerado um doente e passou a alcunha de cliente, ou ainda pior, de consumidor? Esta triste realidade requer profunda reflexão. A natureza da relação médico-paciente encontra-se, cada vez mais, à distância do contato humano. Dizer que hoje, o cirurgião pouco inspeciona, raramente ausculta, percute ocasionalmente e apalpa quando indispensável, não soa exagerado. O fetichismo pela tecnologia, o endeusamento dos métodos diagnósticos complementares desumanizaram os laços necessários com o paciente e a famí$\operatorname{lia}^{3-5}$. Louvemos tais avanços, porém, é preciso estar ciente de que da propedêutica à terapêutica, cada vez mais, equipamentos ou instrumentais interpõem-se entre as mãos do seu operador e o paciente ${ }^{6,7}$. Lembrem-se que estamos nos umbrais da robótica, mas não obstante todas vantagens que dela advirão, o paciente irá, ainda mais, sentir necessidade do conforto da presença humana e do apoio dedicar da figura do médico.

No entanto, como dar compreensão, consolo e atenção se os salários são vis, o atendimento massificado e precário $^{8}$ e os verdadeiros profissionais liberais deixaram de existir décadas atrás? Estes, em sua grande maioria, passaram a constituir o universo dos assalariados indiretos dos serviços públicos, ou enquanto prestadores de serviços para os seguros-saúde, as cooperativas médicas, as empresas de grupo. Alguns dirão que estes dados estão superestimados. Ademais, o bom cirurgião sempre terá um lugar ao sol, movimentará seu consultório e não precisará de outros empregos, haja vista seu reconhecimento pelo mérito. Lamentavelmente, o processo de seleção, afora o dos concursos públicos, não reside na competência, mas em mecanismos, ora perversos, mais preocupados em contemplar o preenchimento de vagas

1. Professor Associado do Departamento de Cirurgia, Faculdade de Medicina, UFRJ.

Recebido em 22/12/2007

Aceito para publicação em 05/02/2008

Conflito de interesses: Nenhum

Fonte de financiamento: Nenhuma 
pela indicação, pagamento de luvas, ou pela influência política. Claro que sempre haverá espaço para o bom propagandista de sua imagem, ou seja, um "marqueteiro" articulado. Ter mérito técnico-científico já não faz a diferença. A carência de profissionais em uma determinada região geográfica muitas vezes é o fator determinante do credenciamento de um cirurgião junto a um convênio.

Há certo constrangimento, entre os cirurgiões, de admitir que não atuam mais em consultório, porquanto mesmo com atividades de pesquisa, docente e ou assistencial, na rede pública, serão considerados, por alguns, como incapazes de galgar êxito na vida profissional. Por outro lado, aos eventuais detratores bem sucedidos, o contra-ataque virá rápido e ferino, pois lhes será imputada a presença de frustração por não pertencerem aos quadros docentes de uma instituição pública. Trata-se de uma polêmica vazia e inócua.

Logo, como investir na formação e qualificação, neste cenário sombrio? Com efeito, a formação do cirurgião geral requer muitos anos de vivencia e treinamento operatórios. Deve ser personalizada e não pode prescindir de atividade constante. Entretanto, não há garantias para uma boa formação cirúrgica, generalista ${ }^{9}$. Os currículos não a contemplam. Mesmo o Internato, em sua fase eletiva, não permite que o aluno alcance competências essenciais para atividades cirúrgicas. Sejamos realistas, há muito tempo as Faculdades de Medicina mal preparam seus egressos para um atendimento primário, em cirurgia. Ao entrar no seu primeiro ano da Residência, o formando precisa rever noções básicas de cirurgia e que, supostamente, já deveriam ser do seu domínio. A pós-graduação stricto-sensu irá exigir mais cinco a seis anos de estudos e pesquisas. Ao final, os pósgraduados já estarão com cerca de 33 a 34 anos, ao passo que, na área básica, não é incomum encontrar-se pós-doutores com 23 a 24 anos. Ademais, ao contrário do que muitos pensam, o Mestrado e Doutorado acadêmicos não têm como desideratos preencher deficiências da Residência Médica, ou complementar a formação assistencial. Significa enveredar pela docência e pela pesquisa (clínica ou experimental), sofrer com a constante falta de recursos, ou conformar-se com a concentração destes para poucos, oriundos de grupos consolidados. Assim, o dilema persiste, pois investir neste rumo, ciente de que esta qualificação de excelência somente será valorizada no interior de uma instituição universitária pública, com remuneração abaixo das expectativas, pode não compensar. Aduz-se que, a opção por tal aprendizado, significaria abrir mão de parte das atividades de consultório e adiar a perspectiva de consolidação de espaços no disputadíssimo mercado de trabalho. O país ainda precisa de Mestres e Doutores. Sem o Mestrado, como renovar o quadro docente das universidades e sem o Doutorado, como formar pesquisadores? Estaria, também, o cirurgião acadêmico em crise ${ }^{10,11}$ ?

\section{O REUNI E OS REFLEXOS NA REORDENAÇÃO DO ENSINO MÉDICO EM CIRURGIA}

Aos nossos pares, cumpre esclarecer que a futura formação do cirurgião poderá estar irremediavelmente com- prometida, se forem implementadas algumas diretrizes previstas no Decreto n ${ }^{\circ} 6096$, de 24 de abril de $2007^{12}$ e que criou o Programa de Apoio a Planos de Reestruturação e Expansão das Universidades Federais- REUNI. Propugna-se, a expansão de vagas e uma relação docente aluno de 1:18, além da ampliação da mobilidade estudantil e criação de cursos noturnos. Tais metas não são adequadas para um curso médico ou outro qualquer na área assistencial. A Medicina e, particularmente, a formação cirúrgica não podem prescindir do desenvolvimento de habilidades e destrezas manuais. A aquisição destas competências exige uma relação tête à tête. $\mathrm{O}$ campo cirúrgico não comporta equipes com mais do que um ou dois alunos (preferencialmente Internos), junto a um docente tutor-operador. Negligenciam-se os valores éticos e científicos e privilegiam-se a expansões desenfreadas com ênfase em relações numéricas de proporcionalidade absurda. Uma visita pré ou pós-operatória ao leito do paciente, na presença de uma multidão a sua volta, respeita a dignidade e a ontética (a ética relacionada ao indivíduo)?

Adotar núcleos comuns de disciplinas para diversas carreiras, sob o pretexto de uma escolha mais amadurecida e assim minimizar a evasão e viabilizar a migração interna, é desconhecer as reais causas da evasão e ignorar a realidade da área de saúde. Raramente há evasão e vagas ociosas na Medicina. Não precisamos de mais médicos, e sim de uma descentralização destes do eixo sul-sudeste, que irá ocorrer desde que haja estímulos adequados. A necessidade de ampliar vagas somente se justifica para o âmbito das Residências Médicas. Criar ciclos compartilháveis irá comprometer a formação do médico e em especial do cirurgião. Este deve aprender e apreender conteúdos disciplinares ministrados com a relevância, profundidade e especificidades inerentes ao futuro exercício do profissional médico. Imaginem a insensatez que se prenuncia, da elaboração de uma ementa de disciplina com aulas comuns, por exemplo, para turmas de Biologia, Medicina, Nutrição. Há mais de duas décadas que o conteúdo das bases morfológicas é ministrado ao Curso Médico, predominantemente, por biólogos, bioquímicos, farmacêuticos, neurocientistas, entre outros. Claro que dentre estes docentes, há os que têm a vocação para o magistério e os médicos devem, também, aprender conceitos fundamentais. Mas a composição química e os mecanismos celulares e moleculares, sem sombra de dúvida, devem agregar conhecimento aplicável à prática futura do médico, o que não ocorre, na maioria das vezes, em face da ausência de professores diplomados em Medicina. A Graduação se transformou no primo pobre, porquanto apenas atrapalha o andamento dos projetos de pesquisa, bem como reduz o precioso tempo destinado à publicação de artigos. É compreensível que tal modelo pedagógico de núcleos comuns tenha muitos defensores, em especial os professores da área básica, posto que, juntar turmas em grandes anfiteatros reduz, convenientemente, o número de aulas e, por conseguinte, o de docentes necessários para ministrálas.

Quanto aos cursos noturnos não há como se aventálos para a carreira médica. Por suposto a atividade de formação cirúrgica irá demandar plantões e operações, madrugada 
adentro, mas tais circunstâncias são emergenciais. Respeitar o paciente, suas horas de repouso, suas angústias, evitar exames sucessivos e coletivos são princípios essenciais para se dar dignidade ao atendimento do enfermo.

Apesar das adversidades, o cirurgião tem uma versatilidade incomum, indispensável para a sua sobrevivência. Para tanto, o cirurgião em formação, antes de tudo, deve ser um bom medico, qualificado e atualizado, crítico, autônomo, responsável e capacitado para o exercício das atividades que se propõe a executar. A escolha dos caminhos profissionais dos cirurgiões quer seja na iniciativa privada ou pública, como docente ou voltado à atividade assistencial, como gestor ou administrador, jamais poderá prescindir da qualificação adequada e do senso ético.

\begin{abstract}
The training of surgeons demands years of expertise and extends far beyond the Graduate Course. The acquisition of skills for the exercise of professional practice will be improved in the Medical Residence, but only the performance in the various scenarios that are presented in the surgical field will prepare them for the operative field stress. The achievement of a Postgraduate course stricto sensu is not enough to give proficiency in order to someone perform an assistance activity; however it could develop a profile for teaching and researching or perhaps it will serve as incentive for a teacher's career option.
\end{abstract}

Key words: Education, medical; Surgeon; Teaching.

\section{REFERÊNCIAS}

1. Schanaider A. A medicina, sua realidade e seus desideratos [editorial]. Rev Cienc Med Biol. 2005; 4(2):1-6.

2. Bueno RRL, Pieruccini MC. Abertura de escolas de medicina no Brasil. Relatório de um cenário sombrio. Brasília: Conselho Federal de Medicina, Associação Médica Brasileira; 2004.

3. Schanaider A. A Importância dos laboratórios de desenvolvimento de habilidades no contexto da cirurgia contemporânea [opinião]. Associação Médica em Revista-SOMERJ. 2004; 1:6-7.

4. Hanly EJ, Marohn MR, Bachman SL, Talamini MA, Hacker SO, Howard RS, Schenkman NS. Multiservice laparoscopic surgical training using the daVinci surgical system. Am J Surg. 2004; 187(4):309-15.

5. Gorman PJ, Meier AH, Rawn C, Krummel TM. The future of medical education is no longer blood and guts, it is bits and bytes Am J Surg. 2000; 180(5):353-6.

6. Schanaider A, Jamel N. Educação à distância em cirurgia: reflexões e desafios. Rev Cienc Med Biol. 2006; 5(1):29-39.

7. Summers AN, Rinehart GC, Simpson D, Redlich PN. Acquisition of surgical skills: a randomized trial of didactic, videotape, and computer-based training. Surgery. 1999; 126(2):330-6.
8. Carneiro MB, Gouveia VV, coord. O médico e o seu trabalho: aspectos metodológicos e resultados do Brasil. Brasília: Conselho Federal de Medicina; 2004.

9. Hossne WS. O cirurgião acadêmico. Acta Cir Bras. 2003; 18(5):372-84,

10. Ahren B. Academic surgery in crisis: a worldwide phenomenon? Does it also affect other disciplines? Nutrition. 1996; 12(3):214.

11. Bland KI. Challenges to academic surgery: the impact of surgical fellowships on choice of an academic career. Bull Am Coll Surg. 2000; 85(4):17-23, 46.

12. BRASIL. Decreto $n^{\circ}$. 6096, de 24 de abril de 2007. Disponível em: <http://portal.mec.gov.br/sesu/arquivos/pdf/diretrizesreuni.pdf> Acesso em:

Como citar este artigo:

Schanaider A. O cirurgião e a atual conjuntura. Rev Col Bras Cir. [periódico na Internet] 2008; 35(3). Disponível em URL: http:// www.scielo.br/rcbc

Endereço para correspondência:

Cidade Universitária - Centro de Ciências da Saúde

Bloco $\mathrm{J}-2^{\circ}$ andar - Cirurgia Experimental

Ilha do Fundão

21944-970 - Rio de Janeiro - RJ1

e-mail: alberto-sch@ig.com.br 